\title{
NOTES ON THE HOP MILDEW (SPHAEROTHECA HUMULI (DC.) BURR. ${ }^{1}$ ).
}

\author{
By E. S. SALMON, F.L.S., \\ Mycologist to the South-Eastern Agricultural College, Wye, Kent.
}

I. On the dehiscence of the perithecium.

IT is only quite recently that the perithecium, ascocarp or sporocarp, as it has been variously called, of the Erysiphaceae has been shown to possess a regular dehiscence accompanied by the ejection of the ascospores. We find the fact first recorded, I believe, by Worthington G. Smith ', in 1884. In 1903 I independently observed the phenomenon in the same species, viz. Erysiphe Graminis DC., which Smith had studied. Smith's observations seem to have been entirely overlooked until attention was called to them in my paper $^{3}$ in 1903 , and up to this date the perithecium of the Erysiphaceae is described in nearly all text-books as a cleistothecium or cleistocarp, since it was supposed to remain closed until it decayed and ruptured to permit of the escape of the ascospores.

The following account of the dehiscence of the perithecium of $E$. Graminis is taken from my paper mentioned above. "It was found that the perithecium opened spontaneously; the ascospores were forcibly ejected into the air, and were found germinating in drops of water condensed on the cover of the Petri dish, at a distance of $2 \mathrm{~cm}$. from the perithecium... The dry perithecium is usually concavoconvex, but on absorbing moisture it becomes biconvex. It opens by a horizontal slit, somewhere about the equatorial plane, at one side. The slit gradually extends further and further round, while the upper half of the perithecium, like a lid, becomes lifted up. This circumscissile dehiscence sometimes results in the upper convex half of the perithecium falling away, and the lower exposed basal half remains fixed in the pannose mycelium. The actual dehiscence is in all probability brought

1 From the Botanical Laboratory, South-Eastern Agricultural College, Wye, Kent.

2 Diseases of Field and Garden Crops, p. 133, 1884.

Joumal of Botany, p. 161, 1903. 
about by the swelling of the mucilaginous cells of the inner wall of the perithecium."

I observed during last spring the dehiscence of the perithecium of the Hop Mildew (Sphaerotheca Humuli (DC.) Burr.). The process is somewhat different from what takes place in $E$. Graminis, as described above. The following experiments were made.

Experiment 1. On April 27 some dried moulded "hops" were soaked in distilled water for a few minutes, and then at once (at 11 o'clock) placed on damp blotting-paper in several Petri dishes. By 7 o'clock, that is, after 8 hours, hundreds of ascospores had been ejected from the perithecia, and were visible in the drops of water which had condensed on the lid. In other cases the lid of the Petri dish had been covered on the inside with a film of agar-agar or of gelatine, and to these also many hundreds of ejected ascospores had adhered. In some cases the ascospores had been ejected to a distance of $1.5 \mathrm{~cm}$. The hops used, which were covered with perithecia, had been taken in January from a stack of hopbine and moulded hops standing in a farmyard, and had been kept dry subsequently in the laboratory.

Experiment 2. On May 1 some dried moulded "hops," obtained and treated as above, were soaked for a few minutes in distilled water, and then at once (at 12 o'clock) placed in the open on the surface of some lately dug ground in a garden. The lid of a Petri dish lined on the inside with a film of gelatine was placed just over the "hops." By 3 o'clock, that is, in 3 hours, hundreds of ascospores had been thrown up from the perithecia, and could be seen adhering to the gelatine. "The ground on which the moulded "hops" were laid was moist, though not very wet. The weather was showery, sunny at times, and with occasional hailstorms; the wind was cold. A fresh lid was placed over the "hops" at 3 o'clock, and by 6 o'clock numerous further ejections had taken place, and hundreds of ascospores were visible on the gelatine film.

Experiment 3. On May 2 some dried moulded "hops" (taken from a stack in April, and kept dry subsequently) were soaked in water for a few minutes, and then a number of perithecia were lifted off with a needle and placed on wet blotting-paper at the bottom of a Petri dish. A cover slip with a thin film of gelatine was supported on a stand at a distance of $1 \mathrm{~cm}$. from the perithecia, and kept continuously under observation. In 35 minutes the perithecia began bursting, and a number of ascospores were shot up on to the gelatine film. At the end of 1 hour some hundreds of ascospores were visible on the gelatine. 
The details of the dehiscence of the perithecium and ejection of the ascospores were then more closely followed. Perithecia were put into a dump chamber or hanging drop of water. In some cases the perithecia which were used were taken straight from a stack of hopbine
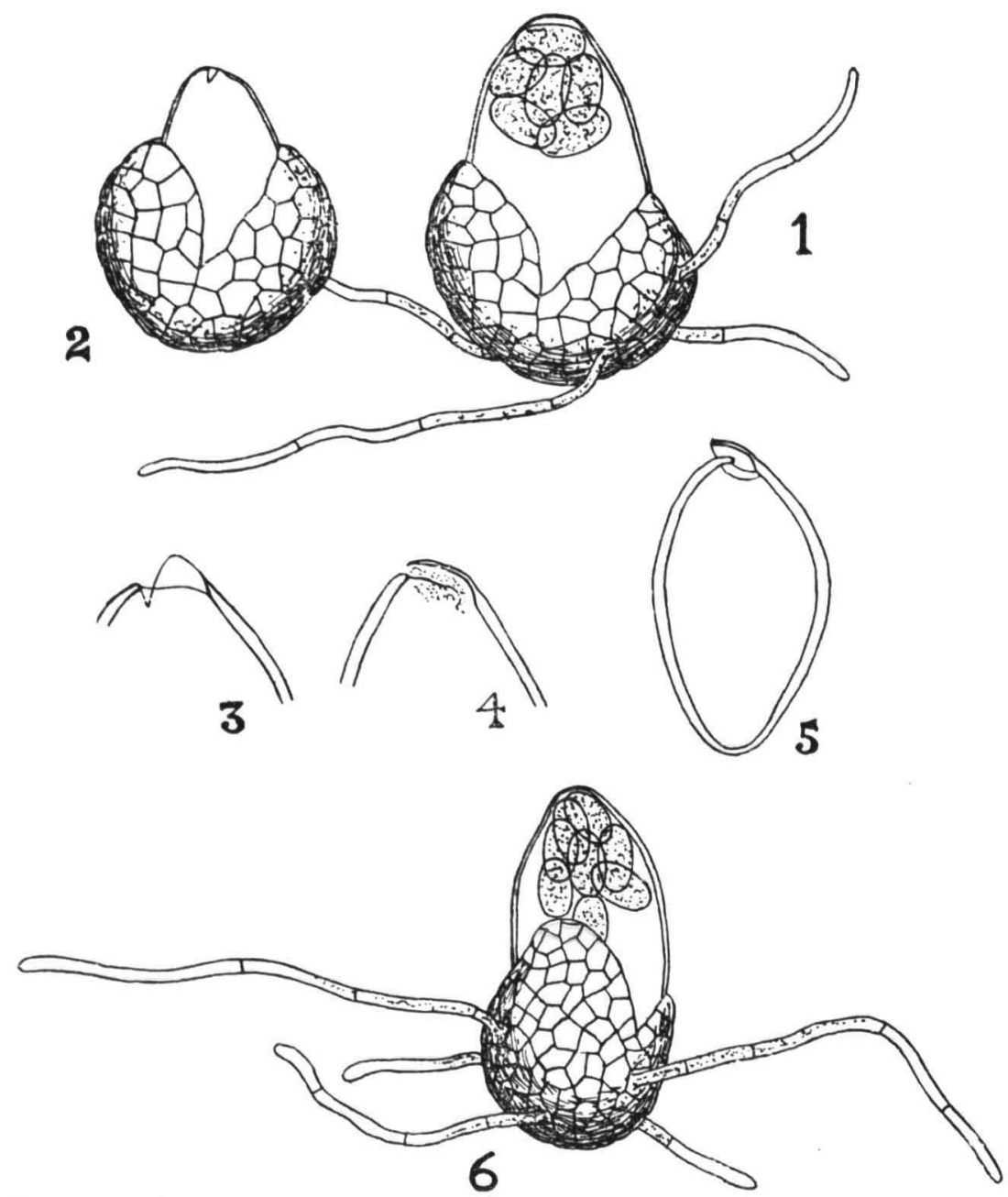

E. S. Salmon delt.

and moulded "hops" in a farmyard; in other cases from moulded "hops "and hop leaves which had been kept dry for some months in the laboratory. The results obtained were the same in both cases. After being kept for a short time (in some cases after 1 hour) in a drop of water, the perithecium begins to split by a more or less vertical 
slit from the apex (see Figs. 1 and 6). At once the apex of the ascus appears at the slit, and the ascus then rapidly swells by taking up water until it protrudes sufficiently to show the enclosed ascospores (Fig. 6). The ascus continues to swell, until it reaches dimensions often considerably exceeding those of the perithecium in which it was originally contained (see Fig. 1). At this stage the walls of the ascus are in a state of considerable tension; the ascospores are usually collected close under the pore at the apex of the ascus (Fig. 1). In a few minutes the ascus bursts by a small slit at its apex (Figs. $3,4,5$ ), and the ascospores are forcibly expelled altogether. The now empty ascus at once contracts and shrinks back into the perithecium, the walls of which come nearer together at the opening. Figs. 1 and 2 show the same perithecium before and after the expulsion of the ascospores; in Fig. 2 the shrunken ascus is seen partly withdrawn into the perithecium. In some few instances, where the perithecium was placed in a hanging drop of water, I have observed the ascus to slip entirely out of the perithecium, soon after the latter has split, before the expulsion of the ascospores. In such cases, which are quite rare, the ascus soon bursts at the apex, as shown at Fig. 5, and discharges the spores,--showing that this process can take place quite independently of the perithecium.

In no instance have I observed any forcible ejection of the ascus from the perithecium, and it seems certain that this does not take place; as a rule the ascus does not even leave the perithecium, but behaves as shown in Figs. 6, 1, and 2. Smith (l.c.) has stated that in $E$. Graminis the asci as well as the spores are ejected from the perithecium, but in my observations on that species I was not able to confirm his statement.

It may be mentioned here that I have not succeeded in inducing perithecia of S. Humuli collected in the autumn to burst and eject the spores before they have passed through a resting period of some months. The perithecia of $E$. Graminis, as I have shown elsewhere, do not require any resting period.

\section{Inoculation experiments with ascospores.}

Experiment 1. On April 21 some dried moulded "hops" were placed on damp blotting-paper in a Petri dish. By April 23 the perithecia had burst, and thrown up many hundreds of ascospores, which could be seen floating in the little drops of water condensed on the lid of the dish. Many of these spores had already commenced 
to germinate. A number of these ascospores were now transferred to the upper surface of a marked leaf of a young (seedling) hop. Seven days later a small patch of Oidium, already powdery with conidia, was visible on the marked leaf, at the spot where the ascospores had been sown.

Experiment 2. On April 29 some hundreds of perithecia which had just arrived at the stage of bursting and ejecting spores, were sown on the upper surface of a marked leaf of a seedling hop, and also of a young plant of Potentilla reptans. By May 6 a fairly large, powdery patch of Oidium had appeared on the hop leaf at the place where the perithecia had been sown. By May 12 this had developed into a large, very conspicuous, white, densely powdery patch. No trace of infection resulted on the $P$. reptans.

Experiment 3. On May 1 a young leaf of a seedling hop and a young leaf of a plant of $P$. reptans-in both cases attached to the plant-were laid upon some moulded "hops" which at the time were ejecting ascospores from the perithecia. The leaves remained in this position for 24 hours, when the two plants were placed under a bell-jar. At the end of 9 days, a vigorous, powdery patch of Oidium appeared on the leaf of the hop. No trace of infection resulted on the leaf of $P$. reptans.

Experiment 4. Another experiment, exactly similar, started on May 2, gave the same results, viz. the infection of the hop, but not of $P$. reptans.

Experiment 5. On May 11 drops of water containing many hundreds of recently ejected ascospores were placed on a leaf of a young hop, and on a leaf of Spiraea Ulmaria, in each case within a marked area on the leaf. On May 21 some delicate radiating mycelial hyphae and a few scattered conidiophores were visible at the marked place on the hop leaf. On May 26 a conspicuous powdery patch of Oidium had developed on the hop leaf at the marked place only. No trace of infection resulted on the $S$. Ulmaria.

Experiment 6. On May 12 conidia were taken from the Oidium patch produced on the hop leaf in the above experiment, and sown on a marked leaf of a hop and on a marked leaf of $S$. Olmaria. By May 26 a powdery patch of Oidium had been produced at the marked place only on the hop leaf; no trace of infection occurred on the $S$. Ulmaria.

We may conclude from the above inoculation experiments that the mildew on the Hop is, at least to a certain extent, a distinct "biologic 
form," since it is unable to infect $P$. reptans and $S$. Ulmaria, both host-plants of the morphological species $S$. Humuli. I have previously shown' that the conidia of the form of $S$. Humuli on $P$. reptans are unable to infect Alchemilla vulgaris, A. arvensis, Fragaria sp., Spiraea Ulmaria, Agrimonia Eupatoria, and Poterium officinale,-all of which are host-plants of the species. The same specialisation of parasitism has been proved (l.c.) to exist in the case of the variety fuliginea of S. Bumuli.

All the evidence, then, shows that the morphological species S. Humuli consists of a number of specialised "biologic forms," each of which is incapable of infecting any of the host-plants of the others. The point is of some economic importance. It has been the habit of agricultural writers who have treated of "hop mildew" or "mould" in connection with the cultivation of hops, to call attention to the fact that this mildew lives on a number of wild plants, such as "Meadow Sweet" (Spiraea) and Avens (Geum); and then, having assumed that the mildew could pass from these plants on to cultivated hops, these writers have advised the hop-grower to spray, or to get rid of, these "mouldy" wild plants?.

From our present knowledge of the specialisation of parasitism of S. Humuli, -as well as of the high degree of specialisation which has been proved to exist in the Erysiphaceae generally ${ }^{3}$ - the hop-grower should not be recommended to take any special steps to deal with mildewed weeds in or near the hop-garden. The whole of the evidence to hand strongly supports the view that hop "mould" is due to one special "biologic form" confined to Humulus Lupulus and H. japonicus, and that consequently hop-growers have nothing to fear from other forms of $S$. Humuli growing on wild plants. It must be pointed out, however, that until inoculation experiments with all the forms of the fungus on the thirty or more host-plants ${ }^{4}$ on which it occurs in this country have been carried out, the bionomics of the morphological species $S$. Humuli must remain only partly known.

1 The New Phytologist, irr. p. 111, 1904.

2 See e.g. Percival, Agric. Botany, p. 732, 1902; Journ. Bath and West of England Soc. xv. p. 78 ; Myrick, The Hop, p. 152 (1899).

s See Salmon, E. S., "Recent Researches on the Specialisation of Parasitism in the Erysiphaceae," The New Phytologist, IIr. p. 55, 1904 ; l.c. p. 109, where a bibliography of the subject is given.

- See Salmon, E. S., Monograph of the Erysiphacese, 1900, and "Supplementary Notes," Bull. Torr. Bot. Club, 1902. 